\title{
Pelvic Inflammatory Disease
}

\author{
Amin Zohra* \\ University Hospitals Plymouth NHS Trust, UK \\ Submission: August 25, 2020; Published: September 07, 2020 \\ *Corresponding author: Amin Zohra, University Hospitals Plymouth NHS Trust, UK
}

\section{Case Report}

(PID) is characterized by an infection-caused inflammatory continuum from the cervix to the peritoneal cavity (endocervicitis, endometritis, salpingitis, peritonitis). Potential consequences of PID include infertility, ectopic pregnancy, chronic pelvic pain, and tubo-ovarian abscess [1]. The sexually transmitted microorganisms Neisseria gonorrhoeae and Chlamydia trachomatis have been isolated from the cervix, endometrium, and fallopian tube of women with histologically confirmed endometritis and visually confirmed salpingitis. They are universally accepted as etiologic agents of PID [1]. Bacterial vaginosis is present in up to two thirds of women with PID [1]. Rarely, respiratory pathogens, e.g, Haemophilus influenzae and Streptococcus pneumoniae, can be isolated from the fallopian tubes of women with salpingitis. The role of IUS/IUD (Intra uterine system/Intra uterine contraceptive device) in increasing the risk of PID have been debated over the last few decades [2]. Although multiple studies have proven IUS not to be associated with increased risk of PID [2,3], some animal studies have suggested presence of an LNG being associated with delayed bacterial clearance [4-8], a higher bacterial burden in early infection (weeks 3-6 after initial inoculation), and an increased incidence of chronic salpingitis in a prospective model of $C$. trachomatis infection $[9,10]$. Multiple RCTs have been conducted suggesting little or no benefit of prophylactic antibiotics prior to insertion of IUCD $[3,4]$ and therefore they are not currently being used in the UK as well as across the globe.

In this case report, we mention the case of a 50 years old woman who had a few risk factors and hence developed severe PID after insertion of IUS for Heavy menstrual bleeding. This is an effort to discuss whether this practice should be reconsidered for selected patients who are at high risk of developing PID.

\section{Case}

A 50 years old woman attended emergency department with complaints of very heavy menstrual bleeding. She was Obese (BMI>30) and known to have Diabetes Mellitus Type
2, Ankylosing spondylitis (AS) and Fibromyalgia. Her regular medications included Omeprazole, Tramadol, Pregabalin, Naproxen, Oral Vitamin D, Fluoxetine, Propranolol, Sumitriptan, Atorvastatin and had used Adalimumab for AS. She previously had one termination of pregnancy and Laparoscopic Appendectomy. TVUSS revealed a $5.7 \mathrm{~cm}$ haemorrhagic cyst in the left adnexa and a $14 \mathrm{~mm}$ submucous Fibroid. She was booked for an Outpatient Hysteroscopy, Endometrial biopsy with insertion of Mirena coil as well as repeat USS in 4 months to ensure resolution of the adnexal cyst.

She attended two weeks after her Outpatient procedure (Hysteroscopy, Pipelle Endometrial biopsy and insertion of IUS) with Suprapubic pain migrating to Left iliac fossa, fever and change in bowel habit. Her blood picture suggested acute inflammation with a white cell count of 17.6, C-reactive protein of 182 and platelets of 548. She was anaemic with a $\mathrm{Hb}$ of $98 \mathrm{~g} / \mathrm{dl}$. A CT Abdomen and pelvis with contrast was conducted for suspicion of? PID /? Diverticulitis. The CT suggested inflammatory stranding in the pelvis surrounding uterus and ovaries. A possible channel was noted from the endometrium through the anterior myometrium which possibly reflected trauma from the endometrial biopsy. The adnexal cystic mass was also demonstrated and remained the same size.

She was given IV followed by Oral Abx and discharged in a couple of days without any other intervention. She was readmitted a month later with pyrexia and ongoing intermittent abdominal pain which had never improved since her previous admission. A repeat USS (TA and TVUSS) revealed a complex cystic lesion within the left adnexa measuring $70 \mathrm{~mm} \times 60 \mathrm{~mm} \times 76 \mathrm{~mm}$ with no Doppler flow. A comment was also made on her increased discomfort during the scan.

After discussing the images with Gynaecologic Radiologist, the cystic structure was considered likely to be tubo-ovarian abcess and a Laparotomy was arranged the next day. The findings at Laparotomy were frozen pelvis with unidentified uterus, ovaries 
and sigmoid. A left adnexal pus collection (green coloured with sweet smell) was identified and drained. The abdomen was closed after a washout. The patient improved afterwards and was discharged home on day 4 post op. On her follow up appointment at 6 weeks post op, she had recovered well with a small peri incisional hernia that did not need any further intervention.

\section{Discussion}

This case describes how a relatively safe gynaecological intervention gave rise to a complication that increased patient's morbidity significantly. Although majority of studies suggest Insertion of IUS to be a safe procedure with little or no effect on PID and use of prophylactic antibiotic being unnecessary, this case is a clear example of the need for modifying this practice according to risk factors. Considering our patient, she had a few risk factors rendering her slightly more immunosuppressed. She had Ankylosing spondylitis and had been on adalimumab injection (although withheld once PID diagnosed). She was also obese with type 2 Diabetes Mellitus which again were potentially affecting her immune response. Although in this case her sexual history was not significant nor was she previously diagnosed with Sexually transmitted infections.

Since this case, we've had two more cases of tubo-ovarian abcess developed after IUS insertion in obese women with other medical conditions that could affect their immune response. Reconsidering the protocol for women based on their past medical history and administering antibiotics might reduce the incidence of these life-threatening Tubo-ovarian abcesses reducing patient Morbidity significantly. To make it cost-effective, a criteria can be designed for women who should or should not receive prophylactic antibiotics. Table 1 suggests some risk factors that could lead to consideration of prophylactic antibiotics.

Table 1: Suggests some risk factors that could lead to consideration of prophylactic antibiotics.

Risk Factors for PID that might need consideration of prophylactic antibiotics

\begin{tabular}{|c|}
\hline antibiotics \\
\hline BMI \\
\hline $\begin{array}{c}\text { Presence of medical conditions that can effect immunity e.g Diabetes, } \\
\text { Use of immunosuppressants (6), HIV (10) etc. }\end{array}$ \\
\hline Endometrial biopsy obtained at the same time as IUS insertion. \\
\hline Previous history of treated Sexually transmitted Infection \\
\hline
\end{tabular}

The table also suggests antibiotics for women who previously had STIs based on studies that compared the incidence of PID with IUS insertion in women with STIs to women without previous/ current STI [8]. It is, however, important to mention here that IUS is altogether contraindicated in women with purulent cervicitis or active cervical chlamydial infection or gonorrhoea. There have been suggestions about pre IUS insertion screening for chlamydia and Gonorrhoea, however no significant difference has been identified in the incidence of PID among screened and unscreened women [7]. Although there have been small studies on some immunosuppressed condition where IUS was shown not to increase the risk of PID, author is still of the opinion that larger trial are needed to assess the effect of IUS in the immunosuppressed as well as the need for prophylactic antibiotic.

\section{Conclusion}

Although there is strong evidence against the use of prophylactic antibiotics before IUS insertion, there is a need for studies focused on immunosuppressed patients. Until then, considering antibiotics for high risk women might prevent significant morbidity in this group of patients.

\section{References}

1. Soper DE (2010) Pelvic inflammatory disease. Obstet Gynecol $116(2$ Pt 1): 419-428.

2. Shelton JD (2001) Risk of clinical pelvic inflammatory disease attributable to an intrauterine device. Lancet 357(9254): 443.

3. Grimes DA, Lopez LM, Schulz KF (1999) Antibiotic prophylaxis for intrauterine contraceptive device insertion. Cochrane Database Syst Rev 2: CD001327.

4. Walsh T, Grimes D, Frezieres R, Nelson A, Al E, et al. (1998) Randomised controlled trial of prophylactic antibiotics before insertion of intrauterine devices. The Lancet 351(9108): 1005-1008.

5. Hubacher D (2014) Intrauterine devices \& infection: review of the literature. Indian J Med Res 140 Suppl(Suppl 1): S53-S57.

6. Ramhendar T, Byrne P (2012) Use of the levonorgestrel-releasing intrauterine system in renal transplant recipients: a retrospective case review. Contraception 86(3): 288-289.

7. Sufrin CB, Postlethwaite D, Armstrong MA, Merchant M, Wendt JM, et al. (2012) Neisseria gonorrhea and Chlamydia trachomatis Screening at Intrauterine Device Insertion and Pelvic Inflammatory Disease. Obstet Gynecol 120(6): 1314-1321.

8. Mohllajee AP, Curtis KM, Peterson HB (2006) Does insertion and use of an intrauterine device increase the risk of pelvic inflammatory disease among women with sexually transmitted infection? A systematic review. Contraception 73(2): 145-153.

9. Eastman AJ, Bergin IL, Chai D, Bassis CM, LeBar W, et al. (2018) Impact of the Levonorgestrel-Releasing Intrauterine System on the Progression of Chlamydia trachomatis Infection to Pelvic Inflammatory Disease in a Baboon Model. J Infect Dis 217(4): 656-666.

10. Morrison CS, Sekadde-Kigondu C, Sinei SK, Weiner DH, Kwok C, et al. (2001) Is the intrauterine device appropriate contraception for HIV-1infected women? BJOG 108(8): 784-790. 
(C) This work is licensed under Creative BY DOI: 10.19080/JGWH.2020.19.55602
Your next submission with Juniper Publishers will reach you the below assets

- Quality Editorial service

- Swift Peer Review

- Reprints availability

- E-prints Service

- Manuscript Podcast for convenient understanding

- Global attainment for your research

- Manuscript accessibility in different formats ( Pdf, E-pub, Full Tsext, Audio)

- Unceasing customer service

Track the below URL for one-step submission https://juniperpublishers.com/online-submission.php 